\title{
Serum lipids in young female survivors of myocardial infarction
}

\author{
J. I. Mann ${ }^{1}$ and Margaret Thorogood \\ with the technical assistance of R. Jelfs and G. R. Whiting \\ From the Departments of Social Medicine and the Regius Professor of Medicine, University of Oxford
}

Fasting serum lipids and lipoprotein patterns were studied in 44 female survivors of acute myocardial infarction under the age of 45 years, and in 84 matched control subjects. Type II hyperlipoproteinaemia was present in $4 I$ per cent of the myocardial infarction patients and in none of the controls. There was, however, no difference in the prevalence of the type IV abnormality, which was present in 7 per cent of the myocardial infarction patients and 8 per cent of the control subjects. Mean cholesterol and triglyceride levels were both significantly higher in the women who had survived myocardial infarction than in the controls; the difference in triglyceride was attributable to the type IIb abnormality which occurred in II per cent of these patients. It is suggested that ovarian hormones may protect premenopausal women from type IV hyperlipoproteinaemia and its possible atherogenic sequelae.

Ischaemic heart disease is more common in men than in women, but this sex difference tends to become less with increasing age. In 1970 the death rate from ischaemic heart disease in England and Wales was about seven times greater in men than in women in each of the ro-year age groups from 25 to 54 years, but in those between 55 and 64 years there was only a threefold difference (Registrar-General's Statistical Review, 1970). The higher incidence in older women, together with the observation that bilateral oophorectomy is associated with an increased risk of myocardial infarction (Parrish et al., 1967; Utian, 197I) suggest that premenopausal women may be protected from myocardial infarction by the ovarian hormones. There is, however, very little published information as to how such a protective mechanism might operate. Knowledge of the frequency of known 'risk factors' for ischaemic heart disease in myocardial infarct patients and in healthy men and in women of different age groups in a susceptible population may be expected to provide some clues. However, because of the relative infrequency of myocardial infarction in young women, very little is known about the prevalence of these factors in premenopausal women who have survived a myocardial infarct compared with a control population. We present here data on serum lipid abnormalities in a group of

Received 7 January 1975.

'Supported by ICI and Cecil John Adams Research Fellowships. young women who survived a myocardial infarct and in a group of matched controls.

\section{Subjects and methods}

\section{Myocardial infarction patients}

Myocardial infarction patients were identified in 2 of the I4 hospital regions of England and Wales which existed until reorganization of the Health Service - North West Metropolitan and Oxford. The study was confined to women under 45 years of age who were discharged from hospital during the years $1968-72$ after a proven diagnosis of myocardial infarction (according to the World Health Organization criteria for this diagnosis) (WHO, 1971). All patients included in the study either had unequivocal electrocardiographic evidence of myocardial infarction (i.e. development of a pathological $Q$ wave or evolution of an injury current which lasted for more than one day), or a typical history of myocardial infarction together with raised serum enzymes and equivocal electrocardiographic changes. All acute hospitals in these areas with more than 300 beds were included in the investigation provided that a satisfactory manual diagnostic index (or a comparable computerized system) was available. There can be little doubt that occasional cases were missed when searching the manual indexes, but it seems unlikely that this could have introduced any element of bias. Sixty cases who fulfilled the study criteria were traced and an attempt was made to obtain a fasting blood sample from each of the patients. Samples were collected after an overnight fast either by the patient's general practitioner or by one of us. We were 
able to obtain blood samples from 44 of the 60 cases $(73 \%)$ and in every instance at least 6 months had elapsed between the time of the acute event and the time the blood sample was taken. Their mean age was 40 years and the range 25 to 44 years.

\section{Controls}

Three control patients, matched for age, marital status, and hospital of admission, were selected randomly for each myocardial infarct patient from a list of previously determined diagnoses which included a wide range of acute medical and surgical conditions and certain elective surgical procedures. The mean age and range were the same as for the infarct patients. An attempt was made to collect fasting blood samples from at least 2 of the 3 controls selected for each myocardial infarct patient and we succeeded in obtaining samples from 84 of these patients. As with the infarct patients, at least 6 months had elapsed between the time of discharge from hospital and the time the blood sample was taken.

\section{Methods}

Total serum cholesterol was measured by the method of Searcy and Bergquist (1960) and triglyceride by the method of Eggstein and Kreutz (1966). Electrophoresis of lipoproteins was carried out on all samples on agarose gel by the method of Noble (r968). Lipid abnormalities were classified as recommended by the World Health Organization (a modification of the Fredrickson classification) (Beaumont et al., 1970). The upper limits of normal for both cholesterol and triglyeeride were set at twice the standard deviation above the mean for our control population. In view of the fact that the skewed distribution of serum triglyceride is normalized by logarithmic transformation (Carlson and Linstedt, I969), all computations relating to this lipid were made with logarithms of the measured values. For clarity of presentation, however, the values obtained for the mean and upper limit of normal have been reconverted to the antilogarithms in Table I (Rifkind, Lowson, and Gale, I968). The significance of differences between myocardial infarct patients and the control patients was calculated by the use of the Mann Whitney $U$ test (Siegel, r956).

The data presented in this paper were collected during the course of a study aimed at determining the relation between oral contraceptives and myocardial infarction (Mann et al., 1975).

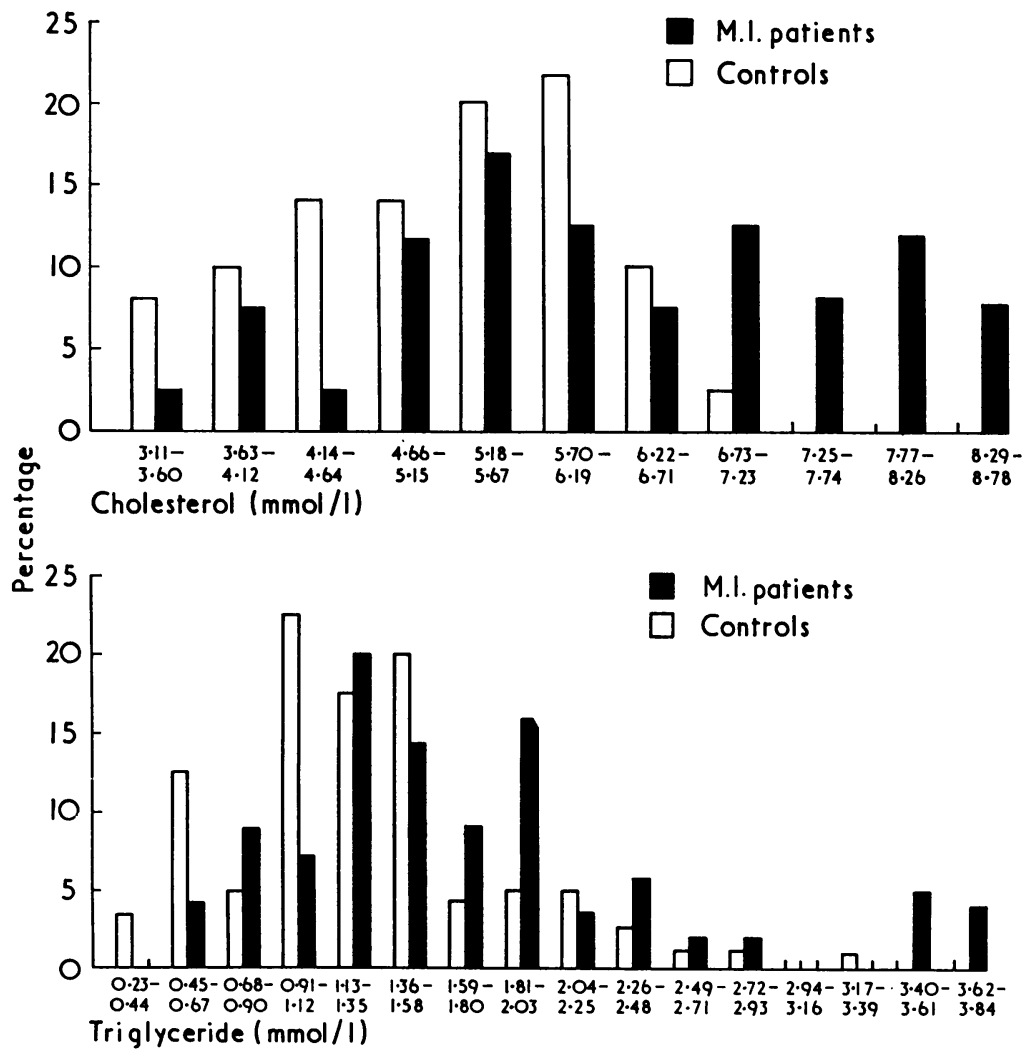

FIG. Distribution of serum cholesterol and triglyceride in myocardial infarct patients and controls. Conversion factors from SI units to traditional units: $\quad$ I mmol/1 cholesterol $38.6 \mathrm{mg} / 100 \mathrm{ml}$. Immol/1 triglyceride $\approx 88.5 \mathrm{mg} / 100 \mathrm{ml}$. 


\section{Results}

Mean levels of serum cholesterol and triglyceride and the upper limits of normal (set at two standard deviations above the mean) are given in Table $I$.

TABLE I Mean levels and upper limits of normal for cholesterol and triglyceride

\begin{tabular}{lll}
\hline & $\begin{array}{l}\text { Cholesterol } \\
(\mathrm{mmol} / \mathrm{l})\end{array}$ & $\begin{array}{l}\text { Triglyceride } \\
(\mathrm{mmol} / \mathrm{l})\end{array}$ \\
\hline $\begin{array}{l}\text { Control patients (mean) } \\
\begin{array}{l}\text { Upper limits of normal (2 SD } \\
\text { above mean) }\end{array}\end{array}$ & 5.05 & $\mathbf{1 . 2 3}$ \\
$\begin{array}{l}\text { Myocardial infarct patients } \\
\text { (mean) }\end{array}$ & 6.92 & 2.34 \\
$\begin{array}{l}\text { Significance level of difference } \\
\text { between myocardial infarct } \\
\text { patients and control patients }\end{array}$ & $\begin{array}{l}\mathrm{P}<0.00 \mathrm{U}=124 \\
\mathrm{Z}=3.03\end{array}$ & $\begin{array}{l}\mathrm{P}<0.02 \\
\mathrm{U}=1440 \\
\mathrm{Z}=\mathbf{2 . 0 5}\end{array}$ \\
\hline
\end{tabular}

Conversion factors from SI units to traditional units:

Cholesterol I mmol $/ 1 \approx 38.6 \mathrm{mg} / 100 \mathrm{ml}$.

Triglyceride I mmol $/ 1 \approx 88.5 \mathrm{mg} / 100 \mathrm{ml}$.

Both lipid levels are significantly higher in the myocardial infarct patients than in the control subjects. Histograms for both lipid levels in myocardial infarct and control patients are shown in the Fig. The most striking change from the distribution in the control population is the shift to the right of serum cholesterol levels of the myocardial infarct patients. A less pronounced shift is apparent in the case of triglyceride.

Table 2 shows the frequency of abnormalities of lipoprotein distribution according to the WHO classification. Type IIa or b occurred in $4 \mathrm{I}$ per cent of the myocardial infarct patients and were not present in any of the control patients, whereas the type IV abnormality occurred in about 7 per cent of the myocardial infarct patients and 8 per cent of the control patients.

Three of the 18 ( 17 per cent) infarct patients with type II a or b hyperlipoproteinaemia had been using oral contraceptives against 8 of the 26 (3I per cent) infarct patients in whom the blood levels were more nearly normal but only 9 per cent of the control patients. The association between oral contraceptives and myocardial infarction is considered in detail elsewhere (Mann et al., 1975). There was no significant difference between the myocardial infarct and control patients with regards to the frequency of premature menopause.

No information is available concerning dietary advice given to the patients with myocardial infarction; however, the fact that 38 per cent of these patients (as compared with I4 per cent of the controls) were eating fewer eggs at the time of study than at the time of admission suggests that many were given at least some dietary instruction. Any change in serum lipids induced by this or other dietary alteration is likely to have reduced the differences demonstrated between the infarct patients and their controls. Mean body weight (at the time of study) was similar to the weight recorded on admission, but the 4 patients who weighed more than $80 \mathrm{~kg}$ at the time of admission had all lost weight at the time of study. One of these patients had type IIb hyperlipoproteinaemia.

\section{Discussion}

Type IIa hyperlipoproteinaemia is characterized principally by an increase in beta-lipoprotein and consequently also by an increase in serum cholesterol, its principal lipid component; type IV by an increase in prebeta-lipoprotein and triglyceride; and type IIb by an increase in both beta and prebeta-lipoprotein and consequently increased cholesterol and triglyceride levels in the fasting serum. In the present study the higher triglyceride levels in the myocardial infarct patients as compared with the control subjects are accounted for by the patients with the type IIb disorder since the type IV abnormality did not occur more frequently among the myocardial infarct patients.

One or other of the two variations of type II hyperlipoproteinaemia was present in over 40 per cent of the myocardial infarct cases and in none of the control subjects. This high prevalence among young female survivors of myocardial infarct is perhaps hardly surprising in view of the welldescribed association between cholesterol or type II hyperlipoproteinaemia and the development of

TABLE 2 Frequency of different types of lipoprotein abnormalities among myocardial infarction and control patients

\begin{tabular}{lccccc}
\hline & Normal & Type IIa & Type IIb & Type IV & Total \\
\hline Myocardial infarct patients & 23 & 13 & 5 & 3 & 44 \\
& $(52.3 \%)$ & $(29.6 \%)$ & $(11.4 \%)$ & $(6.8 \%)$ & \\
Control patients & 77 & 0 & 0 & 7 & 84 \\
& $(91.7 \%)$ & & & $(8.3 \%)$ & \\
\hline
\end{tabular}


ischaemic heart disease in men and older women, an observation that has now been confirmed in prospective studies (Kannel et al., 1971; Carlson and Böttiger, 1972). In view of the fact that the upper limit of serum cholesterol was set at two standard deviations above the mean, it is perhaps surprising that no control patient had the type II abnormality. This may be because with the relatively small numbers studied, only 2 such controls could have been expected on statistical grounds.

Three major controlled studies have recently investigated serum lipids in survivors of myocardial infarction, but both in the American (Goldstein et al., 1973) and in the British (Patterson and Slack, 1972; Lewis et al., 1974a) investigations, the number of premenopausal women studied was too small to draw any helpful conclusions. A recently published report of an uncontrolled series of women under the age of 45 years has been published by Oliver (1974), who found hypercholesterolaemia to be present in 46 per cent of patients who had presented with myocardial infarction or angina.

Perhaps the most interesting finding in the present investigation is the fact that the type IV abnormality did not occur more frequently amongst the myocardial infarct patients than it did among their matched controls, as hypertriglyceridaemia, or type IV hyperlipoproteinaemia, has emerged as an important risk factor for ischaemic heart disease in men and older women in several restrospective studies (Goldstein et al., 1973; Patterson and Slack, 1972; Lewis et al., 1974a; Carlson, 1960; Albrink, Meigs, and Man, I96I) and at least one prospective investigation in which triglycerides were measured (Carlson and Böttiger, 1972).

In order to attempt an explanation of the sex difference in ischaemic heart disease, it is helpful to consider the frequency of risk factors in men and women in the general population. A recent British investigation showed that both type II hyperlipoproteinaemia and hypertension had a similar prevalence among men and women. Type IV hyperlipoproteinaemia, on the other hand, was found to occur much more frequently in men (Lewis et al., 1974b). Brown and Daudiss (1973) found a similar sex difference in the prevalence of type IV hyperlipoproteinaemia in a free-living population in Albany, New York, and in addition noted a tendency for this difference to be less apparent in the 55 to 64 age group It is in this age group that the sex difference in death rates from ischaemic heart disease becomes less obvious (Registrar-General's Statistical Review, 1970). Furthermore, there is no sex difference in ischaemic heart disease death rates in diabetes (Garcia et al., 1974) and while the diabetic state is associated with a wide range of metabolic abnormalities, hypertriglyceridaemia (and type IV hyperlipoproteinaemia) is the most frequently observed derangement of lipid metabolism (Nikkilä and Kekki, I973). These observations suggest that ovarian hormones may exert at least some of their protective effect against ischaemic heart disease by protecting the premenopausal woman from hypertriglyceridaemia. In our study, type IV hyperlipoproteinaemia was present in only 7 per cent of the cases and 8 per cent of the controls, as compared with a frequency of 35 per cent in the cases of women over 45 studied in London by Lewis et al. (1974a).

We are grateful to the many doctors who collected the blood samples, and to Professor Sir Richard Doll, Dr. M. P. Vessey, Dr. T. D. R. Hockaday, and Dr. A. J. Honour for advice and encouragement. Financial support was received from the DHSS.

\section{References}

Albrink, M. J., Meigs, J. W., and Man, E. B. (196I). Serum lipids, hypertension and coronary artery disease. American fournal of Medicine, 31, 4 .

Beaumont, J. L., Carlson, L. A., Cooper, G. R., Fejfar, Z., Fredrickson, D. S., and Strasser, T. (1970). Classification of hyperlipidaemias and hyperlipoproteinaemias. Bulletin of the World Health Organization, 43, 891.

Brown, D. F., and Daudiss, K. (1973). Hyperlipoproteinemia. Prevalence in a free-living population in Albany, New York. Circulation, 47, 558.

Carlson, L. A. (1960). Serum lipids in men with myocardial infarction. Acta Medica Scandinavica, 167, 399.

Carlson, L. A., and Böttiger, L. E. (1972). Ischaemic heartdisease in relation to fasting values of plasma triglycerides and cholesterol. Lancet, $1,865$.

Carlson, L. A., and Linstedt, S. (1969). The Stockholm Prospective Study. Acta Medica Scandinavica, 185, Suppl. 493.

Eggstein, M., and Kreutz, F. H. (1966). Eine neue Bestimmung der Neutralfette in Blutserum und Gewebe. Klinische Wochenschrift, 44, 262.

Garcia, M. J., McNamara, P. M., Gordon, T., and Kannel, W. B. (1974). Morbidity and mortality in diabetics in the Framingham population. Diabetes, 23, 105 .

Goldstein, J. L., Hazzard, W. R., Schrott, H. G., Bierman, E. L., and Motulsky, A. G. (1973). Hyperlipidaemia in coronary heart disease. Fournal of Clinical Investigation, 52, 1533.

Kannel, W. B., Castelli, W. P., Gordon, T., and McNamara, P. M. (I97I). Serum cholesterol, lipoproteins, and the risk of coronary heart disease. Annals of Internal Medicine, 74, $I$.

Lewis, B., Chait, A., Oakley, C. M., Wootton, I. D. P., Krikler, D. M., Onitiri, A., Sigurdsson, G., and February, A. (1974a). Serum lipoprotein abnormalities in patients with ischaemic heart disease. British Medical fournal, 3, 489.

Lewis, B., Chait, A., Wootton, I. D. P., Oakley, C. M., Krikler, D. M., Sigurdsson, G., February, A., Maurer, B., and Birkhead, J. (1974b). Frequency of risk factors for ischaemic heart-disease in a healthy British population. Lancet, I, I4I. 
Mann, J. I., Vessey, M. P., Thorogood, M., and Doll, R. (1975). Myocardial infarction in young women with special reference to oral contraceptive practice. British Medical fournal, 2, 24r.

Nikkilä, E. A., and Kekki, M. (1973). Plasma triglyceride transport kinetics in diabetes mellitus. Metabolism, 22, I.

Noble, R. P. (1968). Electrophoretic separation of plasma lipoproteins in agarose gel. Fournal of Lipid Research, 9, 693.

Oliver, M. F. (1974). Ischaemic heart disease in young women. British Medical fournal, 4, 253.

Parrish, H. M., Carr, C. A., Hall, D. G., and King, T. M. (1967). Time interval from castration in premenopausal women to development of excessive coronary atherosclerosis. American fournal of Obstetrics and Gynecology, 99, 155.

Patterson, D., and Slack, J. (1972). Lipid abnormalities in male and female survivors of myocardial infarction and their first-degree relatives. Lancet, I, 393.

Registrar-General's Statistical Review of England and Wales (1970). Part I. H.M.S.O., London.
Rifkind, B. M., Lawson, D., and Gale, M. (1968). Diagnostic value of serum lipids and frequency of lipoprotein patterns in myocardial infarction. Fournal of Atherosclerosis Research, 8, 167.

Searcy, R. L., and Bergquist, L. M. (1960). A new colour reaction for the quantitation of serum cholesterol. Clinica Chimica Acta, 5, 192.

Siegel, S. (1956). Non-parametric Statistics for Behavioural Sciences. McGraw-Hill, New York.

Utian, W. H. (I97I). Cholesterol, coronary heart disease and oestrogens. South African Medical fournal, 45, 359.

World Health Organization (1971). Criteria for Myocardial Infarction, Ischaemic Heart Disease Register. WHO, Copenhagen.

Requests for reprints to Dr. J. I. Mann, Department of the Regius Professor of Medicine, Radcliffe Infirmary, Oxford. 